\title{
The lexical bias effect in bilingual speech production: Evidence for feedback between lexical and sublexical levels across languages
}

\author{
ALBERT COSTA \\ University of Barcelona, Barcelona, Spain \\ and \\ BJORN ROELSTRAETE and ROBERT J. HARTSUIKER \\ Ghent University, Ghent, Belgium
}

\begin{abstract}
The lexical bias effect (LBE) is the tendency for phonological substitution errors to result in existing words (rather than nonwords) at a rate higher than would be predicted by chance. This effect is often interpreted as revealing feedback between the phonological and lexical levels of representation during speech production. We report two experiments in which we tested for the LBE (1) in second-language production (Experiment 1) and (2) across the two languages of a bilingual (Experiment 2). There was an LBE in both situations. Thus, to the extent that the LBE reveals the presence of interactivity between the phonological and the lexical levels of representation, these effects suggest that there is feedback in second-language production and that it extends across the two languages of a bilingual.
\end{abstract}

One of the most hotly debated issues in language production is how activation spreads through the different levels of representation. Lexical access encompasses the selection of the lexical representations corresponding to the intended concept and, subsequently, the retrieval of the corresponding phonological segments (e.g., Bloem \& La Heij, 2003; Caramazza, 1997; Dell, 1986; Levelt, Roelofs, \& Meyer, 1999). Existing models assume multiple lexical activation during the first stage of processing (e.g., when the picture of a dog is named, several words become activated: dog, cat, lion, etc.). However, different views on how activation percolates to the phonological level have been advanced. Discrete models assume that only the phonological segments of the selected word are activated (e.g., Levelt, 1989; Levelt et al., 1999). In contrast, cascaded models assume that any activated lexical representation (irrespective of whether or not it is finally selected) spreads a proportion of its activation to the corresponding segmental information (e.g., Griffin \& Bock, 1998; Morsella \& Miozzo, 2002; Navarrete \& Costa, 2005).

Cascaded models differ also on whether they assume interactivity (i.e., feedback) between phonological and lexical representations. Whereas feedforward-only models postulate that activation of segmental information does not

This research was supported by Grant SEJ 2005-00409/PSIC from the Spanish government, by Grant BFF2002-10379-E from the European Science Foundation, by the McDonnell grant "Bridging Mind, Brain, and Behavior," and by Grant RGP68/2002 from the HFSP. Also, this research was sponsored by Grant G.0427.04 from the Fund for Scientific Research-Flanders (FWO), awarded to R.J.H. Correspondence concerning this article should be addressed to A. Costa, Dept. Psicologia Bàsica, Universitat de Barcelona, Pg. Vall d'Hebron, 171, 08035 Barcelona, Spain (e-mail: acosta@ub.edu). feed back to the lexical level, interactive models assume that segmental information feeds back to the corresponding lexical items even before they have been selected (e.g., Dell, 1986; Harley, 1993; Rapp \& Goldrick, 2000). Thus, according to interactive models, lexical selection is affected by both the semantic and the phonological systems, since there is feedback from the latter level to the former one. The experimental evidence suggests the existence of some degree of feedback (e.g., Cutting \& Ferreira, 1999; Hartsuiker, Corley, \& Martensen, 2005; Rapp \& Goldrick, 2004; but see Roelofs, 2004).

In this article, we explore the information flow in bilingualism. We address the following two questions. First, is there feedback between the phonological and the lexical levels of representation during second-language (L2) production? Second, does the phonological activation of the lexical representations from the response language feed back to the lexical representations of the non-response language?

Given that current models of bilingual production (e.g., Colomé, 2001; Costa \& Caramazza, 1999; Costa, Caramazza, \& Sebastián-Gallés, 2000; Costa, Santesteban, \& Caño, 2005; Green, 1998; Kroll, Bobb, \& Wodniecka, 2006) assume the parallel activation of the bilinguals' two languages up to the phonological level (cascade nature of the bilingual system), the question can be raised of whether this system honors the interactivity principle as well. And if so, whether interactivity is present only within the phonological and lexical representations of the response language (within-language interactivity), or whether it involves also the representations of the nonresponse language (across-languages interactivity). We will answer these questions by exploring the presence of the so-called lexical bias effect (LBE) in bilinguals. 
The LBE is the tendency for phonological speech errors to result in real words, rather than nonwords, at a higher rate than would be predicted by chance. This effect has been observed in analyses of naturalistic speech error corpora and controlled experiments (e.g., Baars, Motley, \& MacKay, 1975; Dell \& Reich, 1981; Hartsuiker et al., 2005; Nooteboom, 2005) and has been often interpreted as revealing the presence of feedback between lexical and phonological representations (see Vigliocco \& Hartsuiker, 2002, for a review). According to this explanation, the LBE is the automatic by-product of phoneme-to-word feedback, so that lexical representations are primed but representations corresponding to nonwords are not. ${ }^{1}$ The LBE has received a different explanation in the context of discrete models, according to which the effect is a by-product of the workings of a verbal self-monitoring system that selectively filters out nonword errors more often than word errors (e.g., Baars et al., 1975; Levelt et al., 1999).

More recent research has suggested that the presence of an LBE is the result of both feedback and self-monitoring (Hartsuiker et al., 2005). Specifically, these authors elicited speech errors in both a mixed context (containing words and nonwords) and an exclusive nonword context. They observed that the LBE occurred only in the mixed context (more lexical than nonlexical errors). Importantly, context specifically affected the errors with a lexical outcome (many lexical errors in the mixed context, few lexical errors in the nonword context). Hartsuiker et al. (2005) concluded that a monitoring process suppressed the lexical errors in the nonword context but that such a process played no role in the mixed context. An important reason for this conclusion is that the monitor is a controlled process that adapts to the speaking situation. In a nonword context, lexical status is informative that something has gone wrong, and the monitor exploits that information; but in a mixed context, lexical status is uninformative (both words and nonwords may be correct), and the monitor ignores lexical status. Thus, the mixed context is a situation in which there is no monitoring for lexical status, and the LBE obtained there reflects properties of the production system (i.e., feedback) in isolation from any monitoring influences. Thus, we can make use of the $\mathrm{LBE}$ as a signature of interactivity.

In the present experiments, we assessed the presence of an LBE by means of the SLIP task. In this task, participants silently read a series of word pairs presented sequentially. In some trials, a pair is followed by a sound, and the participants are instructed to name it out loud (the critical pairs). The critical pairs can (1) change into two new words when the first sounds of the words are switched (lexical outcome pairs; e.g., darn bore $\rightarrow$ barn door) or (2) change into nonwords when this occurs (nonlexical outcome pairs; e.g., dart board $\rightarrow$ bart doard). To elicit such errors, the pairs are preceded by biasing pairs, whose initial consonants are identical to the ones of the to-beelicited errors (e.g., boat duke for the target darn bore). An LBE is obtained when experimental pairs elicit more errors than do control pairs.

\section{EXPERIMENT 1 \\ Is There Interactivity in Second-Language Speech Production?}

In this experiment, highly proficient Catalan-Spanish bilinguals were asked to perform the SLIP task in their L2 (Spanish). The materials and procedure were the same as the ones in Hartsuiker, Antón-Méndez, Roelstraete, and Costa (2006).

\section{Method}

Participants. Fifty highly proficient Catalan-Spanish bilingual students at the University of Barcelona participated. They had learned their $\mathrm{L} 2$ before the age of 5 and were highly fluent in both languages (a more detailed description of this population can be found in Costa \& Santesteban, 2004).

Materials, Design, and Procedure. Forty-eight disyllabic target word pairs were selected (see Appendix A): (1) 24 lexical outcome pairs that led to words when their first phonemes were exchanged (e.g., dato gama $\rightarrow$ gato dama) and (2) 24 nonlexical outcome pairs that did not result in new words when their first phonemes were exchanged (e.g., daño gallo $\rightarrow{ }^{*}$ gaño *dallo). Exchanges of first phonemes never resulted in Catalan words. The pairs in the different sets were matched pairwise for the frequency, phonology, stress pattern, and word length of each word. For each target pair, there were three biasing pairs that shared either the first consonant and vowel or the initial consonant with the to-be elicited speech error (e.g., gaño dala for the target dato gama). Eighty-seven filler pairs served as fillers.

A pseudorandomly generated stimulus list was constructed in two counterbalanced versions. Each list consisted of 295 word pairs including 24 targets, 72 biasing pairs (of which 48 occurred twice, resulting in a total of 120 biasing pairs), and 87 fillers (of which 64 occurred twice, resulting in 151 fillers). Five biasing pairs were pseudorandomly assigned to the eight positions preceding the target, but the two positions directly preceding the target were always filled with biasing pairs that shared the same consonant and vowel with the to-be-elicited error.

Two counterbalanced lists were created, so that in each list, half of the targets were of the lexical outcome type, and the remaining half were of the nonlexical outcome type. The two lists differed only in the fact that each target pair in the first list was replaced by its matched pair in the second list, so that across the two lists, each target pair occurred once and always at the same position as its matched pair.

The participants were tested individually and were exposed to computer-generated noise. The participants were asked to silently read the word pairs that would appear on the screen and to name out loud those followed by a beep. Each word pair was presented for $700 \mathrm{msec}$ and was followed by a blank screen for $200 \mathrm{msec}$. Tone onset was simultaneous to the offset of each word pair. In order to encourage the participants to speak quickly, a second beep followed the first one after $500 \mathrm{msec}$. The participants were instructed to answer before this second beep. The next word pair appeared automatically on the screen $900 \mathrm{msec}$ after the second beep. This procedure was identical to the one in Hartsuiker et al. (2006).

The participants' erroneous responses were scored as full exchanges (dato gama $\rightarrow$ gato dama), partial exchanges (anticipations, dato gama $\rightarrow$ gato gama; or perseverations, dato gama $\rightarrow$ dato dama), and other errors. The last category included failures to respond, incomplete errors (dato gama $\rightarrow$ gato ...), phonemic errors that had not been primed for (dato gama $\rightarrow$ dalo gama), and errors that contained the primed-for substitutions, but also substitutions in other parts of the word(s) (fonda raja $\rightarrow$ roto fajo). The only errors that were counted in the analyses were, thus, the ones that were primed for.

\section{Results and Discussion}

From the 1,152 target pairs, 946 were named correctly $(82 \%)$. There were 9 full errors $(0.8 \%), 8$ partial errors 
$(0.7 \%)$, and 189 other errors (16\%). The number of errors in each condition (collapsing full and partial errors) was subjected to two Wilcoxon signed ranks tests (by participants and by items). There were more errors in the lexical outcome pairs than in the nonlexical outcome pairs $\left(Z_{1}=\right.$ $2.81, p<.01 ; Z_{2}=2.36, p<.05 ;$ see Table 1 ).

These results reveal a reliable LBE in L2 production: The participants made more errors when the resulting error was an existing L2 word than when it was a nonword. The LBE magnitude was comparable to that observed when the same experiment was conducted with the first language (L1; 21 lexical errors vs. 3 nonword errors; Hartsuiker et al., 2006). Thus, to the extent that the LBE reveals feedback between lexical and sublexical levels, we can conclude that the dynamics of $L 2$ speech production also involve such feedback. We now will turn to the second question put forward above: Is there interactivity across the two languages of a bilingual?

\section{EXPERIMENT 2 \\ Is There Interactivity Across Languages?}

In this experiment, we addressed the question of whether the phonological activation of lexical representations belonging to the response language would feed back to any lexical representation with which it was linked, irrespective of their language membership. To do so, we explored whether, when performing the SLIP task in Spanish, Spanish-Catalan bilinguals would show more errors if the resulting error was a word in Catalan than if it was a nonword.

To assess this issue, it is crucial that the resulting errors from the critical word pairs should consist of words in Catalan and nonwords in Spanish. However, given the large overlap at the lexical level between Spanish and Catalan (about $70 \%$ of the words are cognates), it was impossible to find enough word pairs that met this criterion while controlling for other variables. Thus, we decided to use nonwords for the critical pairs. However, most of the materials used in the experiment were Spanish words ( $82 \%$ vs. $18 \%$ nonwords).

There were two types of critical pairs: (1) pairs in which an exchange between the first two sounds led to Catalan words (nip tas $\rightarrow$ tip nas [ full nose]) and (2) pairs in which an exchange between the first two sound led to nonwords (nil taf $\rightarrow$ til naf). Importantly, the resulting errors in both types of pairs were Spanish nonwords.

\section{Method}

Participants. Forty-six highly proficient Spanish-Catalan bilinguals (half with Spanish as L1 and the other half with Catalan) from the same population as that in Experiment 1 took part in the experiment.

Table 1

Number of Full and Partial Exchanges in the Lexical and Nonlexical Outcome Conditions in Experiment 1

\begin{tabular}{|c|c|c|c|}
\hline Outcome & $\begin{array}{c}\text { Full } \\
\text { Exchange }\end{array}$ & $\begin{array}{c}\text { Partial } \\
\text { Exchange }\end{array}$ & Total \\
\hline Lexical & 8 & 7 & 15 \\
\hline Nonlexical & 1 & 1 & 2 \\
\hline
\end{tabular}

Materials, Design, and Procedure. Twenty-six monosyllabic nonword (in both Spanish and Catalan) target pairs were constructed: Half changed into Catalan words when their first phonemes were exchanged (e.g., nip tas $\rightarrow$ tip nas), and the other half changed into nonwords (e.g., nil taf $\rightarrow$ til naf). The pairs were matched pairwise for phonology and word length. We constructed 3 Spanish biasing pairs for each target pair. The biasing pairs could contain monosyllabic or disyllabic words. Finally, we constructed 65 filler pairs that all consisted of well-known Spanish words and 16 nonword filler pairs. The nonword fillers were used so that not every nonword in the list was followed by a beep (the targets) and so that the participants could not anticipate the target pairs.

A pseudorandomly organized stimulus list was constructed in two counterbalanced versions. Each list consisted of 164 word pairs including 39 biasing pairs (of which 26 occurred twice, resulting in a total of 65 biasing pairs), 16 nonword filler pairs, and 70 Spanish filler pairs (in fact, 65 biasing pairs, of which 5 occurred twice). In the first list, there were also seven targets and 6 control pairs. The two lists differed only in the fact that each target pair in the first list was replaced by its matched pair in the second list, so that across the two lists, each target pair occurred once and always at the same position as its matched pair. In doing so, we ended up with two completely counterbalanced lists.

The context was dominantly Spanish, since fewer than $20 \%$ of all the items were nonwords. Thirteen Spanish filler pairs were used as disguise items (they were followed by a buzz, and the participants had to name them out loud, just as they did the target and control pairs). These items served to mask the setup of the experiment and were of no further importance. Five biasing pairs were pseudorandomly assigned to the eight positions preceding the critical pairs (target or control), but in such a way that the two positions directly preceding the critical pairs were always Spanish biasing pairs. The same procedure as that in Experiment 1 was used.

\section{Results and Discussion}

From the 598 target pairs, 501 were named correctly (84\%). There were 9 full errors $(1.5 \%), 11$ partial errors $(1.8 \%)$, and 77 other errors $(13 \%)$. There were significantly more errors in the lexical than in the nonlexical outcome pairs $\left(Z_{1}=2.50, p=.01 ; Z_{2}=2.12, p<.05\right.$; see Table 2$)$.

These results reveal that despite the fact that the participants were exposed to Spanish biasing pairs and that Catalan was never involved in the task, the participants seem to be affected by the Catalan lexicon, suggesting that Catalan words were activated through the activation of the phonological properties of the target nonwords. Further support for the notion that the error's source is the Catalan word comes from the lack of correlation between cognate status of the source error and error probability. That is, lexical errors for those word pairs that led to errors resulting in cognate words (miu rel $\rightarrow$ riu mel; rio miel in Spanish [river, honey]), account for only 4 out of the 15 lexical errors. The rest of the errors were Catalan words that do not resemble the corresponding Spanish translations (e.g., gos-perro [dog]; prim-delgado [thin]). This suggests that the source of the error was indeed the lexical representations of the non-response language (Catalan), rather than the ones from the response language (Spanish).

\section{GENERAL DISCUSSION}

We explored the presence of LBE in bilingual production. In Experiment 1, we observed an LBE when the 
Table 2

Number of Full and Partial Exchanges in the Lexical and Nonlexical Outcome Conditions in Experiment 2

\begin{tabular}{lccc}
\multicolumn{4}{c}{ Nonlexical Outcome Conditions in Experiment 2 } \\
Outcome & $\begin{array}{c}\text { Full } \\
\text { Exchange }\end{array}$ & $\begin{array}{c}\text { Partial } \\
\text { Exchange }\end{array}$ & Total \\
\hline Lexical & 7 & 8 & 15 \\
Nonlexical & 2 & 3 & 5 \\
\hline
\end{tabular}

SLIP task was performed in L2, replicating the existence of an LBE in Spanish (a controversial issue; see del Viso, Igoa, \& García-Albea, 1991; Hartsuiker et al., 2006). In Experiment 2, we assessed whether the likelihood of committing an error was modulated by whether or not the resulting error was a word in the non-response language. The results also showed a clear LBE. That is, the participants made more errors when the resulting error was a word from the non-response language than when it was a nonword.

These results reveal that interactivity is also a governing principle of the dynamics in L2 production and that it extends across languages. That is, in the course of speech production, the activation of the phonological segments sends feedback to the lexical representations with which they are linked independently of the language they belong to.

A possible caveat of our study is the assumption that the LBE reveals interactivity. From Hartsuiker et al.'s (2005) account, by which the monitor sets functional criteria, it follows that the LBE in an exclusively lexical context (Experiment 1) results from both interactivity and monitoring; in such a context, if an upcoming word is a nonword, it is a sure sign that an error has been made. Thus, in this situation, the monitor magnifies the inherent pattern (see Hartsuiker, 2006). Nevertheless, strictly speaking, the presence of an LBE in this experiment can also be accommodated by a system that implements only monitoring. However, it would be difficult to argue that the results of Experiment 2 were influenced by monitoring, because, on Hartsuiker et al.'s (2005) account, the use of a mixed context of words and nonwords influences the working of the monitor. Since participants have to read Spanish words and nonwords, the monitor cannot make use of lexical status to reject error outcomes. Given the impossibility of using such a cue, it is very likely that the monitor cannot use the language membership cue either and has to set different criteria (e.g., is this the correct sequence of phonemes?). This explanation is predicated on the assumption that although, in principle, it would be useful to suppress errors that are words in the non-response language, the inclusion of nonwords prevents the monitor from using the language membership criteria to do so. This account makes a straightforward prediction: The LBE across languages will be reduced if the experiment contains only words from one language. That is, the production of Cata-

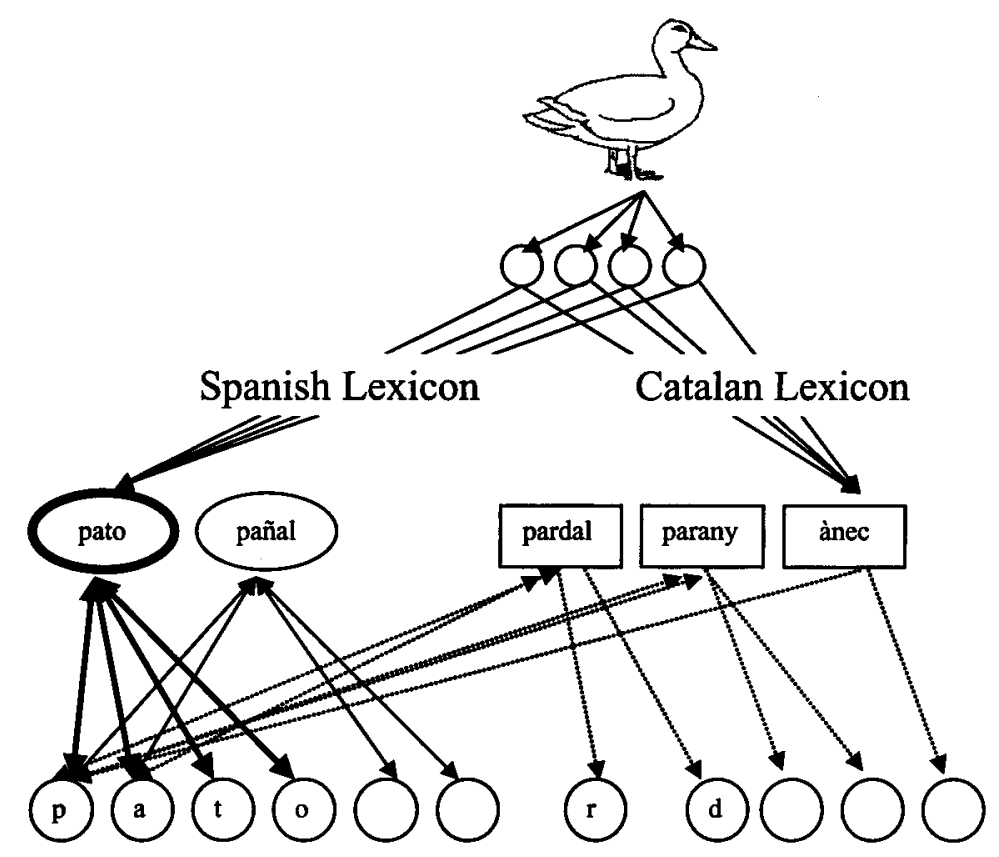

Figure 1. Schematic representation of the lexical system of a CatalanSpanish bilingual in the course of naming the picture of a duck in Spanish (pato). The squares represent the lexical nodes of the language not in use (Catalan), and the circles represent the lexical nodes of the language in use (Spanish). The arrows represent the flow of activation, and the thickness of the circles represents the level of activation of the representations. Note that some lexical representations of the non-response language —Catalan (e.g., pardal [sparrow] and parany [trap])-are activated from the phonological properties of the target word in the response language (Spanish). 
lan errors will be comparable to that of nonword errors if the experiment contains only Spanish words, because, in such a situation, the monitor can reject the Catalan words on the basis of their language membership. Unfortunately, such an experiment is impossible to conduct with the present combination of languages.

The presence of interactivity across languages provides a ready explanation for an interesting effect reported by Kroll, Dijkstra, Janssen, and Schriefers (2000). In this study, Dutch-English bilinguals were asked to name in English a set of pictures that were phonologically very similar across languages ( false friends) but that have different meanings (e.g., lief in Dutch [dear] and leaf in English). Naming latencies for false friends were slower than those for a control set, suggesting that the quasihomophone word in the non-response language is activated through the previous activation of the phonological properties of the target word in the response language.

The observation of an LBE across languages also has implications for the control mechanisms proposed to account for bilingual lexical selection. According to the most prominent model, successful selection of the target word in the response language is ensured by suppressing the activation of words belonging to the non-response language (e.g., Green, 1998; Meuter \& Allport, 1999). That is, the speaker is able to select the target word in his or her L2 (e.g., gos [dog in Catalan]) because the most prominent Ll translation (e.g., perro [dog in Spanish]) is inhibited. In such a view, and contrary to our observations, one should not expect any trace of the lexical representations of the non-response language in the errors produced in the response language. In the light of the available experimental evidence, it is reasonable to postulate a bilingual language production model in which activation is language nonspecific at various levels of representation (see Figure 1): (1) parallel activation of the two languages of a bilingual from the semantic system, (2) cascade activation from the lexical system to the phonological system, and (3) language-nonselective feedback from the phonological representations to the lexical representations (see Costa, La Heij, \& Navarrete, 2006).

To conclude, our results reveal that interactivity between lexical and sublexical representations is a functional principle in L2 speech production and that such interactivity is not restricted to the language chosen for production. The former observation adds to the growing experimental evidence in different domains (e.g., visual word recognition and sentence production) suggesting that bilingual language processing recruits representations of both languages even when only one language is used.

\section{REFERENCES}

BaARS, B. J., MotLEY, M. T., \& MACKAY, D. G. (1975). Output editing for lexical status in artificially elicited slips of the tongue. Journal of Verbal Learning \& Verbal Behavior, 14, 382-391.

BLOEM, I., \& LA Heu, W. (2003). Semantic facilitation and semantic interference in word translation: Implications for models of lexical access in language production. Journal of Memory \& Language, $48,468-488$.
CaramazZa, A. (1997). How many levels of processing are there in lexical access? Cognitive Neuropsychology, 14, 177-208.

CoLomé, A. (2001). Lexical activation in bilinguals' speech production: Language-specific or language-independent? Journal of Memory \& Language, 45, 721-736.

Costa, A., \& Caramazza, A. (1999). Is lexical selection in bilingual speech production language-specific? Further evidence from Spanish-English and English-Spanish bilinguals. Bilingualism: Language \& Cognition, 2, 231-244.

Costa, A., Caramazza, A., \& Sebastián-Gallés, N. (2000). The cognate facilitation effect: Implications for the models of lexical access. Journal of Experimental Psychology: Learning, Memory, \& Cognition, 26, 1283-1296.

Costa, A., LA Heu, W., \& Navarrete, E. (2006). The dynamics of bilingual lexical access. Bilingualism: Language \& Cognition, 9, 137-151.

Costa, A., \& SANTESTEBAN, M. (2004). Lexical access in bilingual speech production: Evidence from language switching in highly proficient bilinguals and L2 learners. Journal of Memory \& Language, 50, 491-511.

Costa, A., Santesteban, M., \& CAÑo, A. (2005). On the facilitatory effects of cognate words in bilingual speech production. Brain \& Language, 94, 94-103.

CutTING, J. C., \& Ferreira, V. S. (1999). Semantic and phonological information flow in the production lexicon. Journal of Experimental Psychology: Learning, Memory, \& Cognition, 25, 318-344.

DELL, G. S. (1986). A spreading activation theory of retrieval in sentence production. Psychological Review, 93, 283-321.

DELL, G. S., \& REICH, P. A. (1981). Stages in sentence production: An analysis of speech error data. Journal of Verbal Learning \& Verbal Behavior, 20, 611-629.

DEL VISO, S., IGOA, J. M., \& Garcfa-AlBEA, J. E. (1991). Autonomy of phonological encoding: Evidence from slips of the tongue in Spanish. Journal of Psycholinguistic Research, 20, 161-185.

GREEN, D. W. (1998). Mental control of the bilingual lexico-semantic system. Bilingualism: Language \& Cognition, 1, 67-81.

GrIFFIN, Z. M., \& Bock, K. (1998). Constraint, word frequency, and the relationship between lexical processing levels in spoken word production. Journal of Memory \& Language, 38, 313-338.

HARLEY, T. A. (1993). Phonological activation of semantic competitors during lexical access in speech production. Language \& Cognitive Processes, 8, 291-309.

HARTSUIKER, R. J. (2006). Are speech error patterns affected by a monitoring bias? Language \& Cognitive Processes, 21, 856-891.

HARTSUIKER, R. J., ANTÓN-MÉNDEZ, I., RoElstraEte, B., \& Costa, A. (2006). Spoonish Spanerisms: A lexical bias effect in Spanish. Journal of Experimental Psychology: Learning, Memory, \& Cognition, 32, 949-953.

Hartsuiker, R. J., Corley, M., \& Martensen, H. (2005). The lexical bias effect is modulated by context, but the standard monitoring account doesn't fly: Related beply to Baars, Motley, and MacKay (1975). Journal of Memory \& Language, 52, 58-70.

KROLL, J. F., BOBB, S. C., \& WoDNIECKA, Z. (2006). Language selectivity is the exception, not the rule: Arguments against a fixed locus of language selection in bilingual speech. Bilingualism: Language \& Cognition, 9, 119-135.

Kroll, J. F., DiJkstra, A., JANSSEN, N., \& SCHRiefers, H. (2000, November). Selecting the language in which to speak: Experiments on lexical access in bilingual production. Paper presented at the 41st Annual Meeting of the Psychonomic Society, New Orleans.

LeVelt, W. J. M. (1989). Speaking: From intention to articulation. Cambridge, MA: MIT Press.

LEVELT, W. J. M., ROELOFS, A., \& MEYER, A. S. (1999). A theory of lexical access in speech production. Behavioral \& Brain Sciences, 22, 1-75.

MeUter, R. F. I., \& ALLPORT, A. (1999). Bilingual language switching in naming: Asymmetrical costs of language selection. Journal of Memory \& Language, 40, 25-40.

Morsella, E., \& Miozzo, M. (2002). Evidence for a cascade model of lexical access in speech production. Journal of Experimental Psychology: Learning, Memory, \& Cognition, 28, 555-563.

NAVARRETE, E., \& Costa, A. (2005). Phonological activation of ignored pictures: Further evidence for a cascade model of lexical access. Journal of Memory \& Language, 53, 359-377. 
NooteвоOM, S. G. (2005). Listening to oneself: Monitoring speech production. In R. J. Hartsuiker, R. Bastiaanse, A. Postma, \& F. Wijnen (Eds.), Phonological encoding and monitoring in normal and pathological speech (pp. 167-186). Hove, U.K.: Psychology Press.

RAPP, B., \& GoLDRICK, M. (2000). Discreteness and interactivity in spoken word production. Psychological Review, 107, 460-499.

RAPP, B., \& Goldrick, M. (2004). Feedback by any other name is still interactivity: A reply to Roelofs (2004). Psychological Review, 111, 573-578.

RoELOFs, A. (2003). Shared phonological encoding processes and representations of language in bilingual speakers. Language \& Cognitive Processes, 18, 175-204.

ROELOFS, A. (2004). Error biases in spoken word planning and moni- toring by aphasic and nonaphasic speakers: Comment on Rapp and Goldrick (2000). Psychological Review, 111, 561-572.

Vigliocco, G., \& HARTSUIKER, R. J. (2002). The interplay of meaning, sound, and syntax in sentence production. Psychological Bulletin, $128,442-472$

\section{NOTE}

1. Most interactive error phenomena have been interpreted in terms of direct feedback - for example, between phoneme and lexical representation-and model simulations (Dell, 1986) have successfully mimicked the data patterns. However, a logical alternative is that there is indirect feedback via the comprehension system (Roelofs, 2004; however, see Rapp \& Goldrick, 2004, for a criticism).

APPENDIXA

Stimuli in Experiment 1

\begin{tabular}{llll}
\hline \multicolumn{2}{c}{ Lexical Outcome Pairs } & \multicolumn{2}{c}{ Nonlexical } \\
\hline rabo & cojo & ramo & coro \\
dato & gama & daño & gallo \\
santa & carta & salto & carne \\
vado & laca & valla & lapa \\
tara & capa & tajo & caja \\
soda & toga & soto & topo \\
bala & sarro & baja & saxo \\
fonda & raja & fósil & rana \\
manco & bando & malva & balde \\
babor & latin & bajel & latón \\
lecho & peña & lento & peca \\
poro & mote & pose & mona \\
lodo & coma & logo & corro \\
cena & pera & ceja & pega \\
pico & riña & pila & rifa \\
manto & tango & manso & tanque \\
moco & pozo & mora & pollo \\
bola & cota & bote & coco \\
palma & calco & parto & carpa \\
seta & miga & sebo & mimo \\
tino & viña & timo & viga \\
losa & coba & lona & copo \\
pazo & cana & paje & caña \\
poda & bolo & pomo & bono \\
\hline & & &
\end{tabular}

APPENDIX B

Stimuli in Experiment 2

\begin{tabular}{clcl}
\hline \multicolumn{2}{c}{ Lexical } & Outcome Pairs & \multicolumn{2}{c}{ Nonlexical } & Outcome Pairs \\
\hline nip & tas & nil & taf \\
glau & blop & glan & blon \\
pos & gou & pord & gog \\
glat & bra & glap & bre \\
miu & rel & min & rer \\
pil & fit & pif & fid \\
cot & bap & cof & bab \\
fel & tar & fep & tad \\
sit & llec & sid & llen \\
top & llap & tol & llad \\
frim & pred & frit & prad \\
noc & fus & nop & fur \\
tent & vant & telt & valt \\
\hline
\end{tabular}

(Manuscript received December 27, 2005; revision accepted for publication April 6, 2006.) 